\title{
Storied images of psychotherapeutic change: Approaching children's voices through drawings.
}

\author{
Claudia Capella ${ }^{1}$, Loreto Rodriguez ${ }^{2 \bowtie}$, Daniela Aguila $^{3}$, Denise Dussert ${ }^{2}$, \\ Ximena Lama ${ }^{3}$, Carolina Gutierrez ${ }^{2}$, \& Gretchen Beiza ${ }^{3}$
}

\begin{abstract}
Introduction: In the field of child psychotherapy research it is common to evaluate psychotherapeutic change through the perspective of adults, such as the child's parents or designated therapist. Research that actively includes children's perspectives of psychotherapy generally turn to verbal methods of gathering information, such as interviews. It is important, however, to take into account non-verbal resources that better facilitate expression among children. Aim: This article explores the use of drawings in order to better understand how children view psychotherapy and psychotherapeutic change. It aims to contribute to child and adolescent psychotherapy research by proposing a new methodology. Method: This study presents a single-case analysis of the "before and after psychotherapy" drawing of an eight year-old boy who was sexually abused and successfully completed the psychotherapeutic process due to this experience. Data collection methods include soliciting a drawing and carrying out an in-depth interview, both of which were examined using thematic and visual narrative analysis. Results: Participant drawing provided crucial insight into the psychotherapy process, such as perceived changes in emotional states and personal growth and empowerment, all of which allowed the child to make sense of the abusive experience. Meanings that emerged when analyzing the drawing complement verbal narratives.Discussion: The implications of these results are discussed, highlighting the importance of non-traditional research methodologies that are sensitive to children's developmental needs. Methodologies that consider the developmental characteristics of children allow them to express themselves fully, articulate their narratives and voices, and allow us to reach an understanding of their meanings of their psychotherapeutic processes.
\end{abstract}

Keywords: single-case analysis, child psychotherapy research, visual narrative analysis

Research on child psychotherapy is growing in the last years. The work of Klein (1984) has pioneered the field, by systematizing the psychotherapeutic experience of a boy. However, research on child psychotherapy, tends to exclude their perspectives, especially of young children (Carlberg, Thoren, Billström \& Odhammar, 2009). According to Bradding and Horstman (1999), researchers have focused primarily on traditional methods such as surveys and clinical interviews to better understand the psy-

\footnotetext{
${ }^{1}$ Department of Psychology - University of Chile

${ }^{2}$ Psychologist, Department of Psychology - University of Chile

${ }^{3}$ Master in Child and Adolescent Clinical Psychology, Department of Psychology- University of Chile

Correspondig Author: Ps. Loreto Rodriguez, University of Chile; email to: loretofrodriguez@gmail.com
}

chotherapeutic process. Indeed, adult perceptions are often privileged, such as the child's parents or designated therapist, and when children are included, researchers tend to rely on verbal strategies to engage with young participants (Heinzel, 1997, in Kuhn, 2003).

When children are interviewed, the brevity of their verbal responses may actually relate more to their ability to retrieve information than to their knowledge or understanding of an event or concept (Driessnack, 2005). Additionally, Fuhs (2000) points to specific challenges that arise during qualitative interviews with children, such as shyness, which often inhibits their capacity for verbal expression.

Carlberg et al. (2009) show the importance of verbal and non-verbal methods for incorporating child perspectives in psychotherapy research. As a 
result, diverse forms of expression among children should be validated because they reflect developmental resources and cognitive and socio-emotional development.

Along this line, authors (Carlberg et al., 2009) have argued that employing non-verbal methods during the interview allow children to naturally express themselves according to their own stage of development. Moreover, such methods reduce suggestion bias and encourage children to respond according to their feelings and not what is expected of them. In this way, drawings and toys serve as tools to help children structure their narratives and provide a space where they feel motivated and present during the interview. These authors delve into the experiences and expectations of children regarding psychotherapy-one example of how different nonverbal techniques encourage children to express themselves (Carlberg et al, 2009).

Related to non-verbal methods, there has been growing interest in the use of art to facilitate communication with children, thereby providing another approach to validating children perspectives (Driessnack, 2005). Visual technics are especially key for the production of information (Harrison, 2002; Lutrell, 2010). Luttrell (2010) states that, "the use of visual methods allows those who might otherwise go unnoticed to be recognized and afforded voice in the body politic" (p.233).

Luttrell (2010) considers children as knowing subjects, underscoring the need for methods that allow children's voices to emerge-voices that are often silenced. In particular, she shows how producing images, such as having children take pictures, allows participants to develop their own voice.

A very common technique in visual methods is "photo elicitation," or the use of photos to guide an interview. Harrison (2002) regards photo elicitation as complementary to in-depth interviews, where reflexivity with the captured image and verbalization provide data for the researcher. In addition, working with images helps to elicit and obtain verbal information; here, narration is essential to understand their meaning.

On another side, visual art techniques such as drawing, as presented by Kuhn (2003), capitalize on children's natural creative impulse and do not require any other stimulus. Drawings are a natural means of expression and a tool for understanding the meanings that children attribute to their experiences.

Drawing is one of the most utilized tools when working with children in both a clinical and research setting (Malchiodi, 1998; Pace, Zavattini \& Tambelli, 2015). Continuing interest highlights the projective value of drawing as well as its contribution to therapeutic processes (Malchiodi, 1998). According to Driessnack (2005), the majority of drawing-based methods aim to uncover the meaning of children's drawings rather than encourage participants to explain their intentions.

Indeed, the projective, psychodynamic-oriented analysis of children's drawings is widespread in clinical psychology research. This longstanding tradition assumes that drawings represent the inner realities and conflicts of children, thus encouraging unconscious associations. This analysis tends to assign symbolic meanings to aspects of drawings that are previously defined (Malchiodi, 1998). As a result, drawings are interpreted by the adult perspective.

On the other hand, Heinzel (1997) calls for a complementary approach to both interviews and drawings - a combination referred to by Fuhs (2000) as the "symbolic form of interview". Here, the act of creating a bridge between how children and adults view the world is key, which would reduce the possibility of an interpretation made only from the perspective of the adult.

According to this latter perspective, the present research study explores the use of visual (drawing) in complement with verbal methods for better understanding how children give meaning to their experiences of change during psychotherapy. It allows for integrated, verbal and visual single-case analysis of a child who successfully completed psychotherapy. In this way, it contributes to the field of research on child psychotherapy.

It advances the role of drawing as a tool for understanding how children view psychotherapy and therapeutic change, therefore proposing a new research methodology for psychological treatment.

\section{Method}

This study is part of a larger qualitative research project titled "Healing Process from Sexual Abuse: Narratives from Child and Adolescent Victims, Their Parents and Psychotherapists". Using a narrative constructivist view that incorporates the perspectives of children and adolescents, their parents and psychotherapists, it explores the healing process from child sexual abuse.

This study involved 27 cases, and in the case of children, the inclusion criteria were children from 8 to 12 years of age who have been sexually abused by a family member or acquaintance, and who have successfully finished their psychotherapeutic process due to this experience in a specialized public center in Chile for the treatment of sexual abuse.

Here we present a single case study for in-depth analysis. Single case studies have been recognized in recent years as important contributions towards building an evidence base for psychotherapy theory and practice (McLeod \& Elliot, 2011; Midgley, 2006; Roussos, 2007). In this manner, research which focuses on an individual allows for greater observations of each case and allows researchers to identify and analyze patterns created by the interplay of different factors (Hodkinson \& Hodkinson, 
2011; McLeod \& Elliot, 2011).

The characteristics of the single case presented below developed out of an interview with the child's psychotherapist, which is part of the larger study.

\section{The Case of José}

The study reported here is centered on a single case analysis of José -to ensure confidentiality his name is a pseudonym-, an eight year-old boy who was sexually abused by two family members (maternal uncle and grandfather) on repeated occasions, also accompanied by serious physical abuse and neglect. At the time of the interview, José had recently successfully completed a psychotherapeutic process due to this experience, which lasted for a period of two years of weekly sessions. His psychotherapy was carried out by a female therapist specialized in child maltreatment and sexual abuse in a public specialized center for treatment of abuse.

When he began treatment, José lived with his father and six year-old sister. He was previously cared for by his mother following his parents' violent separation. José was transferred to his father's custody after episodes of abuse were revealed. His mother did not believe these claims, and as a result, the father chose to take care of the child. He consequently filed a police report regarding the sexual abuse. During the first months of living with José, his father physically abused him, although episodes diminished once he accompanied José to psychotherapy sessions.

José initially presented depressive symptoms, delayed development for someone of his age, and regressive behaviors. José was unable to express himself and his emotions at first, and according to his psychotherapist's account, he presented a serious complexity of psychological dynamics associated with the sexual abuse experience, giving a traumatic meaning to it, specially linked with the perception of helplessness and powerlessness and a perception of the world as a threatening place.

In the early sessions, the psychotherapist worked to establish a therapeutic relationship with José. During the intermediary stages, the child was then encouraged to take on the abusive experience, and acquiring and strengthening personal tools, such as the capacity to express emotions. At the same time, Jose's father participated in psychotherapeutic activities, which aimed to better control his impulses and avoid reaching for violence when reacting to his child. Playtime sessions between the father and child also helped to improve their relationship.

In the final phase of treatment, the psychotherapist noted the impact that therapy had on Jose's development-he was quickly achieving the same developmental milestones as children in his age group- and it decreased significantly the initial de- pressive symptoms. Moreover, José was better able to express his emotions and integrate experiences of abuse into his life story. Also, improved skill development and a more positive view of himself and the world were also observed.

On the other hand, the relationship between José and his father showed significant improvement; the father refrained from acting violently towards his child and was able to develop a connection with José, thereby helping to restore a positive perception of authority figures.

It is also important to note that meanwhile the psychotherapeutic process of the child was developing, the criminal case against his sexual offenders was carried out, and one individual was convicted.

\section{Interview and drawing of "before and after" psychotherapy}

The same as the other children in the study sample, at the end of the therapeutic process, a qualitative interview was conducted with José. To guide this semi-structured interview, an interview script was created, with different interview topics that focused on the child's evaluation of the therapeutic and healing process, as well as the factors he perceived that facilitate or hinder recovery, including themes like psychotherapeutic relationship, techniques in therapy, the conceptualization of healing, personal, familiar, judicial and social factors that mediate recovery, things he/she likes and dislikes of therapy, among others. The interview began with an open question about how was his experience of therapy, and the development of a free narrative by the child was encouraged.

Then a drawing was used to facilitate the child narrative, and regarding the contents the child expressed verbally or through the drawing, the interviewer ask other open questions to explore different topics. The interview was guided by the created script. The interview was held in the same center that the child attended, by a member of the research team specialized in clinical psychology with children, one month after finishing treatment, and had a duration of approximately one hour.

Prior to the interview, Josés father signed a consent form. In addition, the study was explained to the child, who then gave his assent. The research project was approved by the Committee on Ethical Research in Social Sciences and Humanities at the University of Chile, and throughout the research process the wellbeing, willfulness and confidentiality of participants were protected. As part of the larger research project, interviews were initially conducted with the psychotherapist in order to better understand the particularities of each case. Furthermore, an interview with the child's father was conducted at the same time in a separate private room. Finally, the interview was transcribed, and 
the analysis was performed using the transcription.

Drawings were utilized in order to facilitate verbal narratives during the interview with the child; they served as complements to the interview process. The child was asked to draw after the general reason for the interview was explained. The use of drawing, which was later analyzed, helped José develop a narrative about the healing and psychotherapeutic process during the interview.

A specific format was used which required the child to develop a "before and after psychotherapy" drawing. The use of "before-and-after-therapy drawing" is an art technique utilized in therapeutic contexts involving sexual abuse, which has been implemented in Chile (Capella, Escala \& Nuñez, 2014). Together with the participant, the interviewer folds a blank piece of paper in two sections and writes "before" and "after" on each corresponding section. The participant is then invited to draw $\mathrm{him} /$ herself before and after the therapeutic process. Colored pencils, graphite pencil and erasers are provided, which help to spur creativity and spontaneity.

When used in a clinical context, the "before-andafter-therapy drawing" help patients view psychotherapy as a healing and personally empowering period. They may then recognize achievements and important emotional resources associated with the therapeutic process, including the ability to overcome an abusive experience with a new vision of themselves (Capella, Escala \& Nuñez, 2014). The use of such a methodology for research purposes is novel in the present research study and can be valuable to the field of psychotherapy research.

After completing the drawing, open-ended questions were asked, allowing the child to develop a freely structured narrative about different elements of the illustration. More direct and focused questions were then asked regarding the drawing as well as it's overall composition and contextual aspects. Also other questions not related directly with the drawing, related with the topics of the research project were asked to the children during the interview.

At the beginning of the larger research project, researchers considered drawings as a way to facilitate verbal narratives during interviews with small children. However, once the research team saw the powerful impact of drawings and their ability to provide insight into participant narratives, they began to analyze the images as well.

\section{Narrative Analysis}

Narrative analysis was utilized when analyzing research data. This method focuses on how an individual narrates, organizes and evaluates events, and it is proven successful in understanding how individuals give meaning to experiences and personal stories that involve dimensions of time and subjec- tivity (McLeod, 2001; Riessman, 2008). In addition, McLeod (2001) affirms its practicality in studying narratives developed in the context of psychotherapy. Thematic narrative analysis was chosen for the interview process, as it pays attention to the content and meaning of narratives (Riessman, 2008).

Drawings were reviewed using visual narrative analysis (Riessman, 2008). Esin and Squire (2013) adopt a broad definition of a narrative that includes still images. According to the authors, narratives involve a meaningful succession of signs and symbols-visual, verbal, and performed within activities-that progress temporally, causally, or in some other socio-culturally recognizable way, independent of the type of symbols. Thus, visual materials can certainly constitute narratives, independently of the stories about them. Images can also be used as a resource for narrative inquiry; they are a means to construct narratives, assign symbols to experiences, and prompt storytelling (Harrison, 2002), and are tools for meaning making (Radley \& Bell, 2011).

Bell (2013) and Riessman (2008) define visual narrative analysis as an interpretation of the image itself, the context in which it is produced and/or the context in which it is read. Moreover, Radley and Bell (2011) describe the importance of the reader or viewer as an active participant. Riessman (2008) distinguishes between images made by participants in the course of research (used in the present study) and found images.

About the analysis of the image itself, narrative analysis looks at what the image suggests, including how components are organized, how color is used and other relevant aspects depending on the medium (drawing, photograph, film) (Riessman, 2008). The present study uses this type of analysis, paying particular attention to what an image, or drawing in this case, suggests about the therapeutic cha nge process and any changes involved in overcoming sexual abuse. It is key the analysis of the image, specifically on a personal level. Indeed, Riessman (2008) affirms that it is essential to closely reading an image and accessing important details.

In addition, Bell (2013) emphasizes the blurred line between verbal and visual narratives. Different authors have used verbal and visual mediums in conjunction (Radley et al, 2005; Squire et al., 2013). For example, Radley, Hodgetts and Cullen (2005) explain that meaning does not lie within the images themselves, but rather how people perceive or talk about an image, therefore while some of the images may be understandable alone, others may relate to the interview.

Following this guidelines, in the present study, the interview was first analyzed using thematic narrative analysis. This involves that the interview was analyzed looking for emerging themes, which were then organized into different levels of analysis, and into thematic issues at different levels of integration.

Secondly the drawings were analyzed. Analyzing 
drawings required an exploration of the visual narrative itself. This includes a detailed analysis of different aspects and information gathered. First, by observing the central aspect or focus of each drawing (looking at how José draws himself in this case, in each side of the drawing, the before and the after), we can see which is the core element of this visual narrative. Then, attention is given to the surroundings of each drawing, which are the elements of context that are next to the central visual narrative and plays an important role in the configuration of the completed visual narrative and what they can mean. Later, differences and changes between the two drawings (the before therapy drawing, and the after therapy drawi ng) are pointed out, by contrasting the central element (José) and surroundings of the two drawings.

Finally, this was taken together with analyses from the interview in order to form a more complete and integrated narrative, contrasting similarities and differences between the narratives that were observed in the drawing and the themes that appear in the verbal narratives during the interview. Work was performed in team and triangulation was achieved by comparing the analysis of each researcher, thus favoring rigorous and high quality analysis (Yardley, 2000).

\section{Results}

Study results are organized into two sections, which both are related to the process of visual narrative analysis of José's drawing. The first section explores narratives developed in the drawings and analyzes central elements of the figures "before" and "after" and surrounding elements. The second section takes the analysis of visual narratives into account when examining verbal narratives that emerged during the interview. Both visual and verbal narratives are then analyzed in order to see how they complement each other and relate to diverse themes. A separate analysis of the interview and the drawing was made, and then complemented, however the aim of this study, is to present the integrated analysis. Nonetheless, because the aim of this paper is mainly the use of visual methods to understand the experiences of children, the visual will have more attention in the presentation of the results than the verbal analysis.

In order to give a more profound analysis and illustrate the study results, graphic descriptions about the drawing and quotes from the interview are presented, based on the narratives of José, in order to capture his voice. Figure 1 shows the drawing of "before and after therapy" made by José.

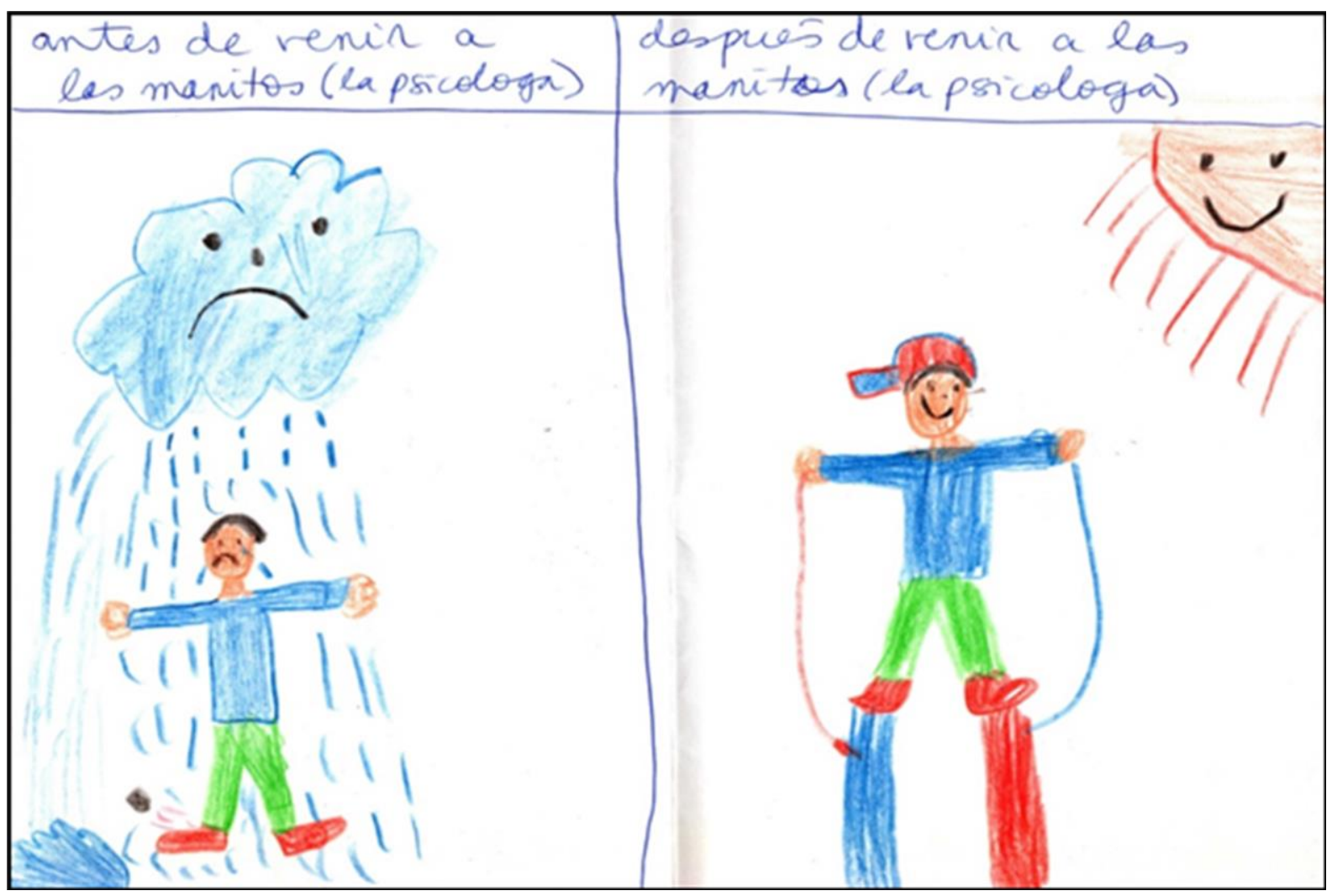

Figure 1: José's drawing

Note. The drawing at the left side said before coming to "the little hands" (the psychologist), and in the right side says after coming to "the little hands" (the psychologist). He calls the child center he attends "the little hands", because the outside wall of the center, has little hands painted. 


\section{What do José's drawing narrate?}

What José says about his own drawing. José is very shy, and during the interview he spoke very little. He was, however, very interested in drawing, which he did in great detail (Figure 1). When he finished his drawing, he folded the paper in two, and developed a cover ("José's before and after") on one side, and wrote "the end" on the other side, as if it were a book.

When asked about his drawing, José said during the interview that he drew a picture of himself sad on the left side because he was sad and in tears over what had happened to him. He drew himself kicking a stone, which is about to fall into a small pond of water. Moreover, he remarked that the cloud was also sad and was crying because of what had happened to him.

On the right side, he commented that he is now happy and bigger, he is standing on stilts, because he likes them and they help him have fun, and has a baseball cap so the sun does not reach his face. $\mathrm{He}$ said that the sun is beautiful and happy.

What José drew. Visual analysis of the "before" drawing reveals a large cloud marked with a sad face, which has dark, bold tear drops that fall onto the child drawn into the picture. These tears form a puddle on the ground, which is the main element in the illustration. The figure of the boy also has a sad facial expression and tears that fall from his cheeks, and this may also be confused with the cloud's own tears. This gives a feeling of being surrounded or completely engulfed in sadness-the predominate mood of the drawing. In addition, the pencil markings outlining the boy are subtle and allow the viewer to see the background of the page; the spatial dimension of the boy in the "before" drawing has a lower size than in the "after" drawing.

In comparison, the "after" drawing provides an upbeat, happy emotional tone, defined by a wide smile and changed facial expression of the boy in the illustration. Moreover, the pencil markings are darker and more defined, although José used the same selection of colored pencils to draw the boy. There are greater dimensions to this figure, and he becomes the protagonist and central element of the drawing. The presence of a sun emerging from one corner and marked with a happy expression contrasts with the large cloud in the "before" drawing. Finally, the figure of the boy in the "after" drawing has new, additional features: a baseball cap and stilts. These are elements that José spoke about during the interview, and they are drawn with the same colors used for the figure.

Analysis of narratives of change according to José's drawing. In José's drawing we can analyze a story of changes. Primarily, the changing visual representation of the boy's figure evokes a sense of progress or evolution in the role he takes "before" and "after" the therapeutic process.

In this way, changing facial expressions shed light on José's changing emotional state-from sad to happy (a sad and tearful face to a smiling and happy face).

Moreover, the dimensions of each drawing shift as the figure of the boy becomes bigger and more dominant, which accounts for a perception of personal growth. In addition to this, the darker pencil markings in the "after" drawing reflect a change in how José views himself. Once a small and almost invisible presence, he becomes empowered, and this is manifested in physical growth.

In addition to changes in how he perceives himself, the use of similar colors and standing position in the "before" and "after" drawings provides a sense of continuity, although the figure in the latter drawing possesses more strength and resources.

For example, the baseball cap is a new element in the "after" drawing, and it provides protection and self-care from the natural environment. The use of stilts speaks to the development of new resources, which allow him to position himself higher and gain a new perspective. The image can be read as a strengthened vision of himself, with a greater set of skills and tools that provide him with new experiences and opportunities. The stilts demonstrate a playful and more youthful side; this shows that José can continue to have a childhood free from the sadness displayed in the "before" drawing.

The changing context is also significant. The drawing's protagonist shifts from the large, sad cloud to the happy sun in the corner. These elements underscore the change in emotional tone as well as a new and improved vision of the worldfrom a threatening world to a more welcoming and accommodating world. In both drawings, contextual elements correspond to the figure's facial expressions, providing insight into a context or environment that is receptive to his emotions.

Thus, it is possible to visualize changes in the figure's face and emotional state, as well as changes in resources and the surrounding environment. However, we can also see continuity in how he views himself; José draws a picture of himself in the same standing position with the same clothing in both the "before" and "after" drawing.

\section{How the verbal and the visual narratives com- plements each other?}

Although the visual narrative emerging from Jose's drawing sheds light on various topics such as emotional change and growth, these were also defined by José during his interview.

José's drawing directly illustrates changes in how the figure of the boy is presented. As mentioned earlier, a changing facial expression of the boy marks a shift in his emotional state (from sad to smiling). This is also expressed in José's verbal nar- 
rative, and aspects related to feeling more upbeat in the present moment reaffirm this change.

The verbal narrative also expresses changes associated with symptomatology during psychotherapy, including a reduction in symptoms that were present beforehand and were reactions to the abusive experience, such as depressive symptoms.

"Interviewer: For some of the time that you've been here you were sad (according to the child's previous descriptions). José: Yes. Interviewer: And what about now? José: Happy."

Additionally, José's view of himself changes, and this is illustrated by the more defined pencil markings and increased physical size of the figure, both of which imply a more empowered and strengthened self-image. About this, the verbal narrative speaks to a vision of personal growth related to psychotherapy. However, it is important to note that José was in treatment for two years, and because the passage of time, he may perceive himself to be bigger now.

\section{"I'm bigger"}

The view of himself as stronger and more equipped with resources is also related to the presence of new elements in the illustration, such as the baseball cap, which acts as a layer of protection. During the interview, José also spoke of how he learned to take better care of himself. He considered this to be one of the most important lessons from psychotherapy. Nonetheless the cap and the verbal narratives guides us to think about the selfprotection strategies he developed, it also can be related to some persecutory feelings and the need to protect himself from abusive contexts.

"Interviewer: And how have you achieved this? (previously in the interview José signals personal strength) José: Caring for myself. Interviewer: How do you take care of yourself? José: I try and make it so they don't hit me...and when they do, I defend myself."

Overall, both the visual and verbal narratives associated with changing contexts are complementary. During José's interview he spoke of empathy and contextual support, and this was also reflected in his visual narrative. The presence of clouds with a mouth and tear-filled eyes in the "before" drawing mirror the face of the crying child in the same drawing. In the "after" drawing, a smiling sun is reflected in the child's smiling face. The shift between before and after therapy shows how José's context is receptive to his emotions - from a sad and emotional context to a friendly one. His verbal narrative about the drawing reaffirms his changing view of the world.

“Because it's a cloud, because I'm sad (...) it's a sad cloud (..) and yeah, I'm missing something, the sun is pretty"

Both verbal and visual narratives present diverse elements that complement each other and form an integrated narrative that makes sense of the meanings José gives to his change throughout the therapeutic process. Nonetheless, the predominance of verbal or visual narratives depends on the ways in which José describes change, and one may be more relevant or powerful depending on the particular topic.

Differences in José's emotional state and perception of the world, as well as new perspectives, change and continuity are most visible in the visual narrative. Mention of greater emotional wellbeing in the present moment was expressed in his verbal narrative, although this narratives of change was also represented visually.

Another important topic was the way he visualized psychotherapy as a process of change, empowerment and capacity of building new resources. This strongly emerges in the visual narrative, and is expressed by new protective elements that allow him to better care for and defend himself. These are also referred to in his interview, although they emerge once José describes his drawing and not as a spontaneous topic. The process of empowerment and skill development is an aspect that is present mainly in José's visual narrative.

José appears to have developed a positive view of himself having overcome experiences of sexual abuse by projecting himself in the future, as he explains in his verbal narrative, with positive characteristics that allow him to now care for and defend himself and others. He expresses an overall view of emotional wellbeing with regards to past experiences of sexual abuse, and he chooses to not remember this experience so often. These topics are present only in his verbal narrative.

"Interviewer: And what do you think you'll be when you're older? José: A policeman. Interviewer: And why would you like to be a policeman? José: because they run fast (...) they run fast and catch bad people."

During his interview, José explores issues that he believes to have facilitated or hindered change and allowed him to overcome sexual abuse and heal from this experience. The role of family support and the psychotherapeutic space emerge as positive aspects of the narratives, and as crucial parts of his growth process. With regards to his family situation, José underscores the importance of feeling supported, protected and cared for by his immediate family-particularly his father-during psychotherapy and in relation to the abusive situation. However, even though he didn't express it during the interview, we can also wonder of possible mixed feelings in the child towards his father during the therapeutic process, in terms that he abused him 
physically, but also is his figure of protection.

Moreover, José describes positive aspects of the therapist and therapy sessions. In this sense, José said that he enjoyed coming to therapy. This is associated with the use of different techniques during sessions such as playtime, because he said that he enjoyed playing with the toys in company of his therapist, and indicated that she was gentle with him. He describes that all these aspects, help him through the process of healing from abuse. These perceptions appear only in his verbal narrative.

"Interviewer: How was beginning to come to therapy? José: great (...) I enjoyed playing with my psychologist. Interviewer: how was she like with you? José: nice, affectionate with me"

Finally, the role of social and legal support emerge as aspects of José's verbal narrative, thereby stressing the importance of the judicial system in helping children who have lived through similar experiences. Along the same lines, José's perception of support and empathy in his surrounding context is reflected in the facial expressions of elements in the drawing (the cloud, sun) as well as verbal expressions during the interview ("sad," "happy").

\section{Discussion}

Based on the results through the analysis of José's drawing, one of the principal conclusions is the positive use of drawing when complemented by the interview process in better understanding children's vision of therapeutic change. Literature on adolescent and child psychotherapy focuses primarily on verbal methods as ways of exploring child narratives (Heinzel, 1997). However, it is necessary to incorporate other forms of interaction and communication that take evolutionary and developmental variables into consideration.

In this way, it becomes increasingly important to include the perspectives of children when carrying out child psychotherapy research, including techniques that adapt and conform to their particular forms of communication and resources. In addition to verbal modes of expression, drawing activities help to access different forms of remembering and internalizing information.

As shown in the present study, the incorporation of visual information allows researchers to better analyze narratives that do not necessarily appear through verbal communication - particularly in the case of young children (Bell, 2013; Esin \& Squire, 2013).

Bell (2013) and Esin and Squire (2013) have raised the point that visual methods can be more effective than the use of interviews alone, which can be restrictive when working with young children. This is supported by Squire et al. (2013), who show that visual narratives are especially important for encourag- ing younger participants to express themselves.

This is evident in the case of José's drawing, in terms that he brings up topics and commentary that were not expressed verbally during the interview. This may be explained by the fact that visual forms of communication allowed José to express meaning in his own language, using symbols and images such as for example, a smile, a sun with a happy face, and changing weather conditions.

The single-case analysis presented here provides insight into a narrative of change that takes place between the "before and after" drawings. This vision of change is expressed mainly through visuals, although it is also complemented by the verbal interview. Both visual and verbal elements regarding the therapeutic process shed light on José's understanding of change - from beginning to end, coinciding with elements outlined in the description of the psychotherapeutic process by the therapist. At the start of therapy, the narrative of the "before" picture presented depressive symptoms in the form of sadness, which was reflected in the illustrated figure's and cloud's unhappy facial expression -both of which speak to a threatening view of the world.

The narrative of change is especially present in the "after" drawing, whereby José illustrates happy, smiling faces and other elements of protection such as a baseball cap to shield him from the sun, to enjoy it without the burn. This may be related to perceptions of changes in his emotional well-being (from sad to happy) and development of new emotional resources. Furthermore, the child said verbally that he was feeling happy during and after his psychotherapy process. The narrative that emerges in José's drawing may be understood as a recovery from depressive symptoms. It also shows that he is able to proceed with development tasks of children his age (building and strengthening tools and emotional resources) and cultivate a more positive view of himself and the world. These elements coincide with the description made by José's psychotherapist about changes in psychotherapy.

On the one hand, José's description of the psychotherapeutic process, as well as problems and associated symptoms, match his visual narrative. The "before and after" drawings allowed José to express his overall conception of change during psychotherapy, and the act of illustrating his vision and point of view according to his own abilities and developmental resources would not have likely been expressed by verbal methods alone, or by other more abstract methods. José was shy and spoke very little, thus the combination of visual and verbal analysis during the interview produced a powerful narrative of change.

On the other hand, emerging narratives in his drawings raise different themes than those produced in the interview. This was observable in the visual analysis of José's drawing. Overall, the visual 
and verbal narratives of José's experience provide insight into the particularities of each method, whereby certain narratives arise from verbal communication, visual expression, or both. This finding extends the reach of narrative studies. Different authors have established the idea that some information appears in visual activities but not verbal interviews (Squire et al., 2013), and that visual methods provide more information than can otherwise be gathered (Readley, Hodgetts \& Cullen, 2005). These narratives do not typically emerge through more conventional verbal means (Esin \& Squire, 2013), particularly because people are better able to make accounts with images (Bell, 2013).

Aspects that forcefully emerge in José's visual narrative and shed light on his psychotherapeutic process are related to changes in his emotional wellbeing, vision of himself and the world, as well as visual continuities and new narratives of empowerment. This emphasizes the use of other forms of communication in order to access the meaning that children ascribe to their processes of change during psychotherapy. Their developmental characteristics mediate how children access abstract categories and concepts, making it more difficult to express them verbally. However, children can express these aspects in a symbolic way, which can emerge in their visual narratives.

Children tend to use symbols from an early age to represent their ideas and the world, and in the developmental stage associated with children like José, this takes the form of concrete operational thinking (Piaget, 1967). In this sense, drawings are important ways of mediating diverse forms of expression and symbolizing, and they are the most natural form of expression among children (Carlberg et al, 2009).

Visual narratives can be analyzed in different ways, and have different meanings depending on their context (Murray, 2000). In this sense, visual analysis of José's drawing was undertaken with the premise that José would give meaning and context to his own illustration. Indeed, once the drawing was finalized, José was asked about specific graphic elements and what they represented for him. This allowed both visual and verbal elements to be used in a complementary manner.

Analyses are enriched when they incorporate what the interviewer and interviewee say about them. For example, José's drawing stiles are better understood when he was asked about it during the interview. If he had not provided this necessary contextualization, perhaps the drawings would have been understood in a different way.

It also emphasizes the idea of the importance to complement the visual analysis of the drawing with what the child says about his drawing. And also to explore more in depth some elements in the interview. While there were elements that emerged only in the visual or verbal narrative, or appeared in both, both narratives taken together produced a more complete and comprehensive view of the psychotherapeutic process and change according to José.

It is important, however, to understand the challenges with interpreting visual narratives. Images may not be easily read (Esin \& Squire, 2013; Squire et al., 2013), because there is no single or correct interpretation of what an image means (Luttrell, 2010). For example, we can assume that José meant to draw rain in the left panel when he really meant to draw a cloud of sadness. Nonetheless, this problem can also present itself when analyzing verbal methods because both visual images and verbal interviews do not necessarily speak for themselves (Luttrell, 2010) and can have multiplicity of meanings (Riesmman, 2008). This can be especially difficult in the case of children, since adults cannot easily approach and understand their perspectives. Indeed, there is a very obvious gap between children's voices and how adult researchers hear them (Luttrell, 2010).

However, integrating visual and verbal information in an analysis using the participant's own reflections about their visual productions allows researchers to understand what the child hopes to express. Indeed, it is possible to make connections between an image and textual data, both of which provide contexts for interpreting the image (Riessman, 2008).

José reveals his perception of change and the psychotherapeutic process through his drawings. This makes the case for using drawing techniques to facilitate children's narratives. Even though this is a single case study, as part of the larger study that included multiple cases, other young participants were also able to visualize and express their thoughts of change through drawings. Of the participants of the study up to ten use this drawing. However it was not possible to present all of them in this study, the analysis of all the children of the study are presented elsewhere (Capella et al., in press).

Narrative analysis of drawings is innovative, seeing as most research using visual methods turn to collages (Esin \& Squire, 2013; Luttrell, 2003, Squire et al, 2013) or photographs (Harrison, 2002; Luttrell, 2010). The level of visual analysis shown in this research is also novel, since "before and after" drawings are typically used in clinical contexts and not research. The fact that this drawing solicited a story, in terms that the headline evokes José's perception of changes during psychotherapy, is also original, and it shows the power of visual narrative analysis. Moreover, it was positive the use of the before and after therapy drawing, because it allows the child to organize his own information and perceptions regarding change by developing a narrativethe primary objective of the present study and the reason for employing this drawing technique.

However, it can also be considered a limitation, 
as the use of a "before and after" drawing implies that the child should express changes perceived to have taken place in a therapeutic context. This may prevent other narratives associated with familial or social contexts to emerge, despite having been influenced or impacted by the therapeutic process. Moreover, because the "before and after" drawing was made at the end of the psychotherapeutic process, this takes the risk of an idealized description of the end of this cycle, where probably the child need a sense of a positive closure of the therapeutic process, thus may have overrepresented positive changes and shadowed negative aspects, with is an important limitation to be considered especially in the case of children.

Therefore the use of drawings, and specifically, the "before and after" therapy drawing, can be considered a useful clinical method to perceive the visions of children regarding change in psychotherapy, and also as a proposal of this paper, a start point to the construction of a research protocol in child psychotherapy research, that could be further developed in future studies.

It would be interesting to apply different directions to the drawing process in future studies in order to understand the multiple factors that influence how children perceive change and psychotherapy. For example, it might be interesting, in future studies, to use the "before and after therapy drawing" at the beginning of the psychotherapy process, in order to explore initial emotions and expectations of change. Also, it could be interesting to explore the use of a revised version of this same drawing in different moments of therapy (how the child view him/herself at the beginning of therapy, and how he/she sees himself at the present moment he/she is in therapy), which can allow us to understand the expectations of the process or their view of change at different time moments. Also, we can use different drawings, that can be useful to explore the view of the therapeutic relation, the therapeutic process, etc. (for example, a drawing of him/herself and his/her therapist, a drawing of him/herself in therapy, etc.). The use of these drawings can have a clinical application, but can also be useful in child psychotherapy research, were the drawing used will depend on the goal of the research study. In the case of the study presented here the goal was to shed light into the process of recovery from sexual abuse, thus, we focus on a drawing that ask for a narrative of changes.

There are others methodological limitations with regard to the present study that must be considered. This paper has the same limitations typical of single-case studies. Issues of internal validity remain one of the greatest challenges, in the sense that there are often different ways to present the same set of issues with different emphasis or approach, and because researchers expertise is an important part of the case study approach, since they decide how represent stories, and what issues and data to include and what to exclude (Hodkinson \& Hodkinson, 2001). Even when the validity of clinical data derived from controlled or formal single-case research is conceded, there are continued critiques of this methodology (Jones, 1993), such as the difficulty of extrapolation or generalizing the results.

Despite these limitations, the present study contributes to our understanding of psychotherapeutic change from the perspective of children (Calberg et al., 2009). These perspectives are relevant to include in psychotherapy research (Carlberg et al., 2009), hearing their voices (Luttrell, 2010). However, to do these, we need to use methods that are closer to their forms of communication, such as drawing and other visual or non-verbal techniques, which allow us to analyze narratives that may not be apparent in verbal communication alone. These may be especially true for young children (Carlberg et al., 2009; Esin \& Squire, 2013; Squire, Esin \& Burman, 2013. Furthermore, this study could orient and address future investigations in the field, by introducing novel methodologies and analysis strategies, and also the possibility of including the perspectives of even younger children by utilizing these and other techniques.

\section{Acknowledgements}

The authors acknowledge that the research presented in this paper was partially funded by: Program UINICIA VID 2012 grant U-INICIA 5/0612; Academic Productivity Support Program PROA VID 2014 University of Chile; and CONICYT Project Fondecyt $\mathrm{N}^{\circ} 11140049$. Also we want to thank Corinne Squire for her contributions in developing the analysis presented in this paper.

\section{References}

Bell, S. (2013). Seeing narratives. In: Andrews, M., Squire, C. $\&$ Tamboukou, M,. Doing narrative research ( $2^{\circ}$ edition). Sage: London.

Bradding A. \& Horstman M. (1999). Using the write and draw technique with children. European Journal of Oncology Nursing 3, 170-175.

Capella, C., Lama, X., Rodríguez, L., Águila, D., Beiza, G., Dussert, D. \& Gutiérrez, C. (in press). Winning a race: Narratives of Healing and Psychotherapy in Children and Adolescents Who Have Been Sexually Abused. Journal of Child Sexual Abuse.

doi: 10.1080/10538712.2015.1088915

Capella, C., Escala, C. L. \& Núñez, L. (2014). Intervención psicoterapéutica con niños y niñas que han sido víctimas de agresiones sexuales: Profundización en el uso de técnicas [Psychotherapeutic treatment with children that have been victims of sexual abuse: deepening the use of techniques]. Curso de actualización de Postítulo, Universidad de Chile.

Carlberg, G., Thoren, A., Billström, S. \& Odhammar, F. (2009). Children's expectation and experiencies of psychodynamic child psychotherapy. Journal of Child Psy- 
chotherapy, 35(2), 175-193.

Driessnacks, M. (2005). Children's drawings as facilitation of communication: A meta- analysis. Journal of Pediatric Nursing, 20(6), 415-422.

Esin, C. \& Squire, C. (2013). Visual Autobiographies in East London: Narratives of Still Images, Interpersonal Exchanges, and Intrapersonal Dialogues. Forum Qualitative Sozialforschung / Forum: Qualitative Social Research, 14(2), Art.1.

Fuhs, B. (2000). Qualitative Interviews mit Kindern. Uberlegungen zu einer schwierigen Methode. In Friederike Heinzel (Ed.), Methoden der Kindheitsforschung. Ein Uberblick uiber Forschungszugänge zur kindlichen Perspektive (pp.87-104). Weinheim, München: Juventa.

Harrison, B. (2002). Photographic visions and narrative inquiry. Narrative Inquiry, 12(1), 87-111.

Heinzel, F. (1997). Qualitative Interviews mit Kindern. In Barbara Friebertshäuser \& Annedore Prengel (Eds.), Handbuch Qualitative Forschungsmethoden in der Erziehungswissenschaft (pp.396-413), Weinheim, München: Juventa.

Hodkinson, P. \& Hodkinson, H. (2001). The strength and limitations of case study research. Paper presents to the Learning and Skills Development Agency Conference. Making an Impact on Policy and Practice, Cambridge.

Jones, E., Ghannam, J., Nigg, J. T. \& Dyer, J. F. P. (1993). A Paradigm for Single-Case Research: The Time Series Study of a Long-Term Psychotherapy for Depression. Journal of Consulting and Clinical Psychology, 6(3), 381- 394.

Klein, M. (1984). Narrative of a Child Analysis. The Conduct of the Psycho-Analysis of Children as seen in the Treatment of a Ten year old Boy. The free press: New York.

Kuhn, P. (2003). Thematic Drawing and Focused, Episodic Interview upon the Drawing-A Method in Order to Approach to the Children's Point of View on Movement, Play and Sports at School [50 paragraphs]. Forum Qualitative Sozialforschung / Forum: Qualitative Social Research, 4(1), Art. 8, http://nbn-resolving.de/urn:nbn:de: 0114-fqs030187.

Luttrell, W. (2003). Pregnant bodies, fertile minds. New York: Routledge.

Luttrell, W. (2010). "A camera is a big responsibility": A lens for analyzing children's visual voices. Visual studies, 25(3), 224-237.

Malchiodi, C. (1998). Understanding children's drawings.
New York: The Guilford Press.

Midgley, N., Target, M., Smith, J. (2006). The outcome of child psychoanalysis from the patient's point of view: A qualitative analysis of a long-term follow-up study. Psychology and Psychotherapy: Theory, Research and Practice, 79(2), 257-269.

McLeod, J. (2001) An administrative reality: some problems with the use of self-report questionnaire measures of adjustment in counselling/psychotherapy outcome research. Counselling and Psychotherapy Research, 1, 215-226.

McLeod, J. \& Elliot, R. (2011). Systematic case study research: a practice oriented introduction to building an evidence base for counselling and psychotherapy. Counselling and Psychotherapy research, 11(1), 1-10.

Murray, M. (2000). Levels of narrative analysis in health psychology. Journal of health psychology, 5(3), 337-347.

Pace C.S, Zavattini G.C., Tambelli R. (2015). Does Family Drawing assess attachment representations of lateadopted children? A preliminary report. Child Adolescent Mental Health, 20(1), 26-33.

Piaget, J. (1967). Six Psychological Studies. Toronto: Random House.

Radley, A. \& Bell, S. (2011). Another way of knowing: Art, disease and illness experience. Health, 15(3), 219-222.

Radley, A., Hodgetts, D. \& Cullen, A. (2005). Visualizing homeless: A study in photography and estrangement. Journal of community \& applied social psychology, 15, 273-295.

Riessman, C.K. (2008). Narrative methods for the human sciences. California: Sage Publications.

Roussos, A. (2007). El diseño de caso único en investigación en psicología clinica. Un vínculo entre la investigacion y la practica clinica [The single case design research in clinical psychology. A link between research and clinical practice]. Revista Argentina de Clínica Psicológica, 16(3), 261-270.

Squire, C., Esin, C. \& Burman, C. (2013). "You are here": Visual autobiographies, cultural-spatial positioning, and resources for urban living. Sociological research online, 18 (3), 1.

Yardley, L. (2000). Dilemmas in qualitative health research. Psychology and Health, 15, 215-228.

Submitted: July 2015 Accepted: October 2015 Published: December 2015 